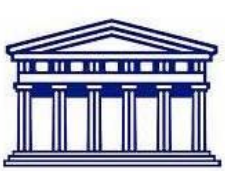

UNIVERSITY of the WESTERN CAPE

\title{
An instrument to determine the technological literacy levels of upper secondary school students
}

\author{
Melanie B. Luckay and Brandon I. Collier-Reed
}

\begin{abstract}
In this article, an instrument for assessing upper secondary school students' levels of technological literacy is presented. The items making up the instrument emerged from a previous study that employed a phenomenographic research approach to explore students' conceptions of technology in terms of their understanding of the nature of technology and their interaction with technological artefacts. The instrument was validated through administration to 1,245 students on completion of their 12 years of formal schooling. A factor analysis was conducted on the data and Cronbach alpha reliability co-efficients determined. The results show that a five-dimension factor structure (namely, artefact, process, direction/instruction, tinkering, and engagement) strongly supported the dimensions as developed during the original phenomenographic study. The Cronbach alpha reliability co-efficient of each dimension was satisfactory. Based on these findings, the instrument has been shown to be valid and reliable and can be used with confidence.
\end{abstract}

\section{Introduction}

The inclusion of Technology as a defined subject area in schooling (Tamir 1991; Waetjen 1993; Gagel 1995, 1997; Lewis 1999) emerged strongly in the 1990s (cf. Compton and Harwood 2003; Williams 2005, Jones et al. 2013). South Africa was a country to follow suite during this time (Ankiewicz 1995; Pudi 2007; van Rensburg et al. 1996) and throughout multiple revisions of the national curriculum (Department of Education 1997, 2002, 2011; Stevens 2005; Potgieter 2012), the primary aim has explicitly been to produce technologically literate students. However, defining technological literacy has proven to be "unexpectedly complex and difficult" (Gagel 1997, p. 1). It has been argued that being literate in technology means that you have proficiency and knowledge, beyond the focus on artefacts and techniques of technology, but with more focus on the knowledge and inventiveness that is technology (Gagel 1997). For students, a simplistic view of technology has the potential to reduce the concept of technology to raw materials-"stuff that we can transform into artefacts" (Dakers 2006, p. 2). For a more sophisticated way of conceptualising about technology, students' thinking should encompass an awareness of the knowledge and processes that are involved in the creation of artefacts, as well as the implications thereof (ITEA 2000). 
Recent research suggests that teachers seldom integrate all the outcomes from educational policy documentation into actual lesson plans (see for example, Potgieter 2012). Thus an important question could be how to monitor students' development of technological literacy as they proceed through a curriculum. An instrument able to quantify levels of technological literacy in students could help improve the teaching and learning of Technology in general, and accordingly inform curriculum, classroom pedagogy as well as help focus teacher education in this area. However, our review of the literature suggests that existing instruments of this nature are not necessarily able to give a holistic view of what it means for students to be technologically literate. Notwithstanding that much of these limitations centre on the multiple meanings of the nature of technology, it is important to ask whether a single instrument can address this question satisfactorily as it has been suggested that a robust instrument to assess technological literacy is, to date, still generally lacking (Gagel 1997; Garmire and Pearson 2006). This article describes how it has been possible to develop such an instrument-one that is valid, reliable and satisfactorily able to holistically assess students' levels of technological literacy.

\section{Theoretical framing}

Technology education curricula in schools are typically underpinned by studies on what it means for students to be technologically literate. These studies draw on experts' understandings of the field and are informed by the philosophers of technology, learned and professional societies, etc. However, we argue that as the literature has included multiple different understandings of the nature of technology and what it means to be technologically literate (for example, Waetjen 1993; Gagel 1995, 1997; ITEA 2000; Garmire and Pearson 2006), a "one size fits all" definition is difficult to articulate-and problematic to implement in a school curriculum. Indeed, students who engage with technology, both inside and outside of the classroom, seldom passively receive knowledgethey interact with it (Jenkins 1997) and selectively develop their understanding of the nature of technology through being influenced in their everyday life experiences thereof.

If one now makes use of a survey instrument to attempt to understand how levels of technological literacy are developing in students, researchers' expectations about what it means to be technologically literate may be differently framed to students' internalised understanding of the nature of technology and what it means to be technologically literate. An analysis of prior research, particularly those using surveys (for example Bame and Dugger Jr 1989; Boser et al. 1998; Garmire and Pearson 2006; Rose and Jr Dugger 2002;

Rose et al. 2004; Volk et al. 2003), suggests evidence of this possible different framing. For instance, some researchers (for example Garmire and Pearson 2006; Volk et al. 2003) suggest that empirically, surveys are unlikely to give a holistic picture of students' levels of technological literacy.

Many surveys appear to only partially combine the dimensions of knowledge, capabilities, and critical thinking and decision-making (NRC 1996; Garmire and Pearson 2006)which have been argued to present a unifying view of technological literacy (Garmire 
and Pearson 2006). Here, the three major components or dimensions of technological literacy are combined where knowledge includes both factual knowledge and conceptual knowledge; capabilities relate to how well a person can use technology (defined in the broadest sense), and critical thinking has to do with ones approach to technological issues. This three-part model was further developed in a study by Collier-Reed (2006), who defined technological literacy as 'understanding the nature of technology, having a hands-on capability and capacity to interact with technological artefacts, and ... be able to think critically about issues relating to technology' (p. 15), a view that has been adopted for this current work.

A challenge is to quantify students' levels of technological literacy using this definition when many surveys measure only a single dimension thereof; which has been described as an 'alternative way to assess technological literacy' (Boser et al. 1998, p. 5). Indeed, a substantial amount of literature reports on surveys that measure attitudes towards technology (see for example, Bame and Dugger Jr 1989; Boser et al. 1998; Garmire and Pearson 2006; Rose and Jr Dugger 2002; Rose et al. 2004; Volk et al. 2003). The Pupils' attitudes towards technology (PATT) questionnaire (Raat and de Vries 1985) is one of the best known technology-related survey instruments. In its early form, the questionnaire included an essay (qualitative) section with questions derived from the literature as well as through interviews with professionals in the field-primarily reflecting the aforementioned expert view of technology. Results in the USA (Bame and Dugger Jr 1989) suggested that this qualitative section of the original instrument was not well understood by those completing the questionnaire and in Hong Kong (Volk et al. 2003) for example, this section was explicitly excluded from the study. We suggest that one of the reasons for there being difficulty with this qualitative section is that it is possible that the students could not distinguish the concept scales they were asked to consider as they were developed from 'expert views'. As such, there may have been a disjuncture between how researchers described an aspect of technology and how students understood or interpreted what was described. More recently, Ardies et al. (2013) "reconstructed and revalidated" the PATT survey, but it is our contention that the survey remains largely based on experts' discourse around technology.

Another significant study that has investigated students' levels of technological literacy was undertaken in 2001 by Saskatchewan Education in Canada. In this study, they looked to assess students' levels of technological literacy and provide 'a snapshot of their skills, knowledge, attitudes and practices' (Saskatchewan Education 2001, p. 1). For this investigation, they define technologically literate students as students that have the ability to 'understand how technology and society influence one another and ... [are able to] use this knowledge in their everyday decision making' (p. 1). One feature of the Saskatchewan Education data collection process worth noting is the assessment criteria against which levels of capacity and capability of the pupils were measured. These consisted of a set of levels developed by the 'stakeholder representatives' (Saskatchewan Education 2001, p. 62) that included various civil society and governmental organisations with educational as well as technical expertise. These are, as such, an 'expert' scale (cf. the PATT 
questionnaire) against which to judge levels of capability and capacity. However, there is no guarantee that students in upper secondary schools will conceive of technology or interact with technological artefacts in terms of the levels developed by the stakeholders- a situation borne out by the nature of some of the results that emerged.

Based on a growing body of evidence, we argue that making use of experts' views of what it means to be technologically literate for use in the development of a survey instrument has the potential to be problematic. We suggest that the results that emerge are influenced by students simply not understanding, or indeed recognising, some of the more advanced conceptions-dimensions-of technological literacy. What may have been more relevant, or useful, would have been to determine, from the students' perspective, the range of ways that it was possible to conceive of technological literacy and then to base the dimensions used in the instrument on this scale. Some researchers (for example Trigwell 2000, 2002; Prosser and Trigwell 1999) have used phenomenography to determine students' conceptions of various phenomena in this way. Phenomenography is an empirical research tradition commonly used in the educational context (Marton 1986). For a phenomenon, there are a limited number of qualitatively different ways that this phenomenon could be conceived and phenomenography describes the variation in conceptions of this phenomenon across a group of individuals; as a collective (Dall'Alba et al. 1993; Trigwell 2000; Collier-Reed and Ingerman 2013).

Phenomenographic research has as its outcome a set of categories that characterise the variation in the ways a phenomenon can be conceived. This 'complex' of categories form what is referred to as an outcome space where the categories will be logically related to one another, both internally and between categories. Once the outcome of a phenomenographic analysis has been finalised in terms of categories, an instrument could be developed where the dimensions-which would develop out of the categories-would then be directly reflective of students' conception of that phenomenon. Phenomenography has been used in this way (Prosser and Trigwell 2004, 2006) to develop an instrument called the Approaches to Teaching Inventory. Similarly, Collier-Reed (2006) used the phenomenographic research approach to explore students' conceptions of technology. The study was conducted to understand how upper secondary school students in grades 11 and 12 conceive of, and interact with, technology; which he argued captured the key dimensions of what it was to be technologically literate. The outcome of that investigation (see for example Collier-Reed 2006; Collier-Reed et al. 2009; Ingerman and Collier-Reed 2011) informed the present study in the development of an instrument to assess students' levels of technological literacy.

\section{Developing the instrument}

This article focusses on the validation of a widely-applicable and distinctive survey instrument for assessing students' levels of technological literacy. The development and validation of the instrument has drawn extensively on our prior work in this area (Luckay and Collier-Reed 2011a, b). In earlier work, as described above, dimensions of technological literacy were developed which Collier-Reed (2006) argued collectively satisfied

\section{http://repository.uwc.ac.za}


the core requirement for what it means to be technologically literate. Using a phenomenographic analysis of interview data, five qualitatively different ways of conceiving the nature of technology, and four qualitatively different ways of conceiving interacting with technological artefacts (Collier-Reed et al. 2009) were described-and are shown in Table 1.

Table 1 Categories based on the outcome of the phenomenographic analysis (Collier-Reed 2006)

\begin{tabular}{ll}
\hline Categories \\
\hline Nature of technology & Technology is conceived of as: \\
An artefact \\
The application of artefacts \\
The process of artefact progression \\
Using knowledge and skill to \\
develop artefacts; and \\
The solution to a problem \\
Interaction with a technological \\
artefact is through: \\
Direction \\
Instruction \\
Tinkering; and \\
Engaging
\end{tabular}

In order to classify students' responses relative to these categories, a series of statements describing the dimensions of technological literacy were developed. To ensure congruence between the students' responses and the categories, sections of an interview relating to a specific category were 'assigned' to a dimension. These interviews were then reanalysed, finally resulting in a number of clearly defined statements (nominally in the students' own words) pertaining to each category.

As an example of how a section from an interview was used in the development of a statement, consider the following extract that was classified as belonging to the category 'Technology is conceived of as an artefact':

Well, it's a bit complicated, firstly. It's very technological. It's exactly what I was talking about, what I said complicated wires and things that you don't understand, it looked like technology (Collier-Reed 2006, p. 123 - Italics in original).

From this interview extract, the following representative statement was constructed: Things with complicated wires and parts that you don't understand are technology representing a particular student-held view of technology. Importantly, this process ensured that the statements derived from this process were the students' own comments, and are thus in a style to which they can relate. Consequently, the original pilot instrument was defined by 41 
statements constructed in this way. There were 25 statements relating to experiencing the nature of technology, and 16 statements relating to the experience of interacting with technological artefacts. After refinement of the original instrument, where the focus was also on clarity and readability of items, the revised instrument was made up of 30 questions and was shown to be valid and reliable (Luckay and Collier-Reed 2011a, b)-with data being collected from 1,064 students across two pilots. These students were drawn from the Engineering and the Built Environment, Commerce, and Humanities faculties as well as from various senior secondary-schools in order to ensure as far as possible the generalizability of the results.

During the first pilot (Luckay and Collier-Reed 2011a, b), the instrument was administered to 435 students early in their first year of study at the University of Cape Town and before they had meaningfully engaged with any tertiary-level material. The groups were split between Engineering (198) and Commerce (237) students. Exploratory factor analysis supported the existence of six dimensions, offering notational support for the distinctions between artefact, process, direction, instruction, tinkering and engagement-cf. the categories shown in Table 1. These findings were used to refine the item pool for clarity. Items that showed factor loadings $\backslash 0.3$ were deleted from further analyses. The result of the first pilot was a 23-item survey, which was adjusted to a 30-item survey after some of the items were re-considered and reworded for conceptual clarity where appropriate to ensure that the items better fitted the dimension.

Two additional pilots were conducted in order to further clarify the dimensions after the modifications had been made. In the second pilot, the 30 item survey was administered to 629 upper secondary school and first-year university students. The group was diverse consisting of students at the end of their schooling and those entering their first year of university. Additionally, the students at university were from diverse faculties, namely, engineering, commerce and the arts. Exploratory factor analysis suggested that a five rather than a six dimensional solution was more interpretable in terms of the factors formed (Luckay and Collier-Reed 2011b). The direction and instruction scales came together during the factor analysis, suggesting that students regarded direction and instruction in similar ways and a new combined scale was formed. Moreover, the factor analysis suggested that three items be removed as their loadings were $\backslash$. .3. However, after careful reflection, we elected to retain the three items as it helped to provide enhanced conceptual clarity.

In the third pilot, the 30-item instrument was used to collect data from 969 students at the University of Cape Town (Luckay and Collier-Reed 2012). The sample was drawn from the Engineering and the Built Environment (312), Health Sciences (80), Science (289) and Humanities (288) faculties. Participants were required to supply biographical information including their age, gender, current degree programme, and upper secondary school attended. 
The final confirmatory study of the instrument was conducted using the 30-item instrument that was analysed during the third pilot. Data were collected from 1,245 students within their first 3 weeks of study at the University of Cape Town. The sample was drawn from the Engineering and the Built Environment (310), Health Sciences (189), Science (288), Commerce (175) and Humanities (283) faculties. Participants were required to supply biographical information including their age, gender, current degree programme, and high school attended. From this information, it was determined that the sample consisted of 587 (47.5\%) males and 648 (52.5\%) females-15 students did not indicate their gender. The average age of the students was 19.13 years $(\mathrm{SD}=0.5)-25$ students did not indicate their age.

The instrument was administered by us to ensure consistency in the instructions given to the students and to answer possible queries. Participants were required to mark on a sevenpoint Likert scale (Cohen et al. 2000) their level of agreement with each item on a scale ranging from strongly disagree to strongly agree. The data collected from the students were used to examine the validity and reliability of the instrument. As a first step, a factor analysis was performed to cluster variables (Field 2005). The sample size for the present study was appropriate to perform such an analysis as Tabachnick and Fiddell (2007) suggest that 'it is comforting to have at least 300 cases' (p. 613). Additionally, Nunally (1978) recommends that the ratio of the items to subjects is ten to one, that is, 10 cases for each item to be factor analysed. Others have suggested 5 cases for each item (Tabachnick and Fiddell 2007). The data collected thus meet the requirements for both sample size and case to item ratio.

\section{Results}

The data were collected from 1,245 students across five faculties at the University of Cape Town and used to examine the validity and reliability of the instrument by performing a principal component factor analysis followed by a varimax rotation.

During analysis of the previous pilot data (Luckay and Collier-Reed 2012), careful attention was given to the dimension engaging as it manifested itself in the data. In the original phenomenographic analysis from which this dimension developed, engaging with a technological artefact was described as taking 'place in the context of self-initiated free enquiry with prior experience being drawn from, and supplemented as required, to inform the interaction' Collier-Reed (2006, p. 101). The original study suggests that this dimension is an advanced conception; a view supported by an analysis of the data. Removing the questions associated with this factor in a five factor solution resulted in a four factor solution emerging. A careful re-examination of the data suggests that Engaging is probably experienced by a minority of the sample. However, as this factor is very likely (as argued in the original phenomenographic study from which these dimensions emerged) to contribute to the overall profile of a students' technological literacy, the dimension was retained in the current analysis. 
Table 2 shows the outcome of the analysis of the data collected. A full description of the questions associated with each item number in the table can be found in "Appendix". Overall, the percentage variance accounted for by the different scales ranged from 4.25 to $18.81 \%$, with a total variance accounted for being $45 \%$. Table 2 also shows that the eigenvalues ranged between 1.28 and 5.05 for the five dimensions.

For the revised instrument, the Cronbach alpha co-efficient was used as an index of scale internal consistency. Careful analyses of the factor loadings as well as the Cronbach alpha co-efficients of all the dimensions indicated that it would be appropriate to retain all but one of the items in the instrument. Table 3 shows that the internal reliability (Cronbach alpha coefficient) ranged between 0.61 and 0.83 . Overall, these results indicate that the internal consistency for the instrument is satisfactory (Field 2005; Kline 1999).

Taken together, the results for the factor analysis, as well as the index of scale reliability (Cronbach alpha reliability index) suggest that the instrument is reliable and valid to use for upper secondary school and first year university students. The final version of the instrument thus consists of 29 items and is presented in "Appendix".

\section{Discussion and concluding remarks}

The development and validation of the instrument-to determine students' levels of technological literacy-is timely given the renewed focus internationally on the importance of developing a technologically literate youth (Ingerman and Collier-Reed 2011). The instrument was rigorously developed, captures the important dimensions of technological literacy, and provides educators and researchers with an accessible means of determining students' levels of technological literacy. The factor structure for the instrument shows congruence with the nature of the categories that emerged from the original phenomenographic analysis that underpins this instrument. All items have a factor loading of at least 0.33 on their a priori scale and no other scale. Furthermore, the internal consistency reliability estimate (Cronbach alpha coefficient) for each of the dimensions of the instrument was comparable with prior studies. 
Table 2 Factor loadings for a modified version of the instrument $(n=1,245)$

\begin{tabular}{|c|c|c|c|c|c|}
\hline Item no. & Artefact & Process & Direction/instruction & Tinkering & Engagement \\
\hline 27 & 0.74 & & & & \\
\hline 25 & 0.68 & & & & \\
\hline 29 & 0.60 & & & & \\
\hline 03 & 0.59 & & & & \\
\hline 14 & 0.38 & & & & \\
\hline 28 & & 0.71 & & & \\
\hline 26 & & 0.63 & & & \\
\hline 19 & & 0.63 & & & \\
\hline 23 & & 0.59 & & & \\
\hline 09 & & 0.57 & & & \\
\hline 10 & & 0.47 & & & \\
\hline 01 & & 0.45 & & & \\
\hline 15 & & 0.44 & & & \\
\hline 11 & & & 0.74 & & \\
\hline 20 & & & 0.74 & & \\
\hline 24 & & & 0.56 & & \\
\hline 16 & & & 0.48 & & \\
\hline 30 & & & 0.46 & & \\
\hline 22 & & & 0.41 & & \\
\hline 12 & & & 0.38 & & \\
\hline 17 & & & 0.33 & & \\
\hline 02 & & & & 0.74 & \\
\hline 05 & & & & 0.63 & \\
\hline 07 & & & & 0.62 & \\
\hline 18 & & & & & 0.73 \\
\hline 21 & & & & & 0.62 \\
\hline 13 & & & & & 0.56 \\
\hline 06 & & & & & 0.56 \\
\hline 04 & & & & & 0.38 \\
\hline$\%$ Variance & 7.11 & 10.52 & 18.81 & 5.17 & 4.25 \\
\hline Eigenvalue & 2.14 & 3.16 & 5.05 & 1.55 & 1.28 \\
\hline
\end{tabular}

Table 3 Cronbach alpha coefficient for the instrument

\begin{tabular}{|c|c|c|c|}
\hline Category & Scale & No. of items & Cronbach alpha coefficient \\
\hline \multirow[t]{2}{*}{ Nature of technology } & Artefact & 5 & 0.61 \\
\hline & Process & 8 & 0.67 \\
\hline \multirow[t]{2}{*}{ Interacting with a technological artefact } & $\begin{array}{l}\text { Direction/ } \\
\text { instruction }\end{array}$ & 7 & 0.83 \\
\hline & Tinkering & 4 & 0.66 \\
\hline
\end{tabular}


The original interviews used to develop the questions in the instrument were conducted with participants who came from diverse cultural and socio-economic backgrounds. Furthermore, the data used in validating the instrument were likewise collected. This notwithstanding, it is recognised that there may be cross-cultural limitations to using statements developed and validated in this way. One approach to addressing this possible limitation would be to have the instrument translated and back-translated across different contexts to better understand the cultural nuances in the items.

The authors' previous work (Luckay and Collier-Reed 2011a, b, 2012) has described how the original dimensions that emerged from the phenomenographic study are currently represented in the factors. These factors usefully straddle the product/process divide with respect to the nature of technology on the one hand and students who shy away from interacting with technological artefacts versus those who are uninhibited in their interaction with these artefacts through tinkering on the other.

For the scale direction/instruction, in the first pilot (Luckay and Collier-Reed 2011a), the results suggested that the scale Instruction was less useful as a stand-alone scale. However, in the second pilot (Luckay and Collier-Reed 2011b), and in the present study, the reliability co-efficient suggest that combining the scales direction/instruction was more meaningful (the Cronbach alpha reliability was 0.83-see Table 3). Interestingly, the fact that the two scales merged in the factor analysis (Table 2) suggest that the students could not distinguish between whether the teacher or facilitator was directing them or instructing them in their interaction with an activity. Students see direction described by Collier-Reed (2006) as:

The result of a directive by someone. It is not something that happens spontaneously as there is reluctance to making the first move toward approaching it. This category describes the experience as being on the outside looking in towards a technological artefact as a reified object, the artefact is placed on a 'pedestal' in an exalted, unapproachable position ( $\mathrm{p}$. 298).

Collier-Reed (2006) described Instruction as 'receiving instruction via some means which enables the interaction with the artefact' (p. 299). Thus, it could be that students preferred being helped or guided to ways of initiating their interaction with a technological artefact. It is likely that these students lacked the spontaneity to interact with a technological artefact independently. The results from this study could have implications for both professional development programs for teachers as well as classroom practices. This instrument provides an important means of monitoring teaching-particularly in cases where there is a blurring between directing and instructing students. Here, teachers might adjust their learning environment towards a more focused promotion of a technologically "safe" environment. 
The scale Tinkering plays an important role in distinguishing groups. This scale is described by Collier-Reed (2006) as:

[C]haracterised by a self-initiating interaction with a technological artefact by beginning to tinker with it...[T]here is no need for instruction to enable the interaction. There is no sense of being intimidated by anything to do with the artefact...[They] recognise that an artefact has a variety of functions and set out to determine what they are and make the artefact operate (pp. 299-300).

The fact that students are able to self-initiate their interaction with a technological artefact implies that these students have moved beyond being directed or instructed to interact with an artefact. They most likely have the skill, ability and understanding to interact with an artefact in a more sophisticated way. Thus, it could imply that whatever level of academic development, some students have an innate ability to interact with a technological artefact, without being initiated by some form of direction or instruction from an outside source. Students who have the ability to self-initiate through tinkering may be better candidates for technical programmes, like Engineering. In fact, comparing the technological literacy of students across faculties, Luckay and Collier-Reed (2011b) found that Engineering and Science students are more likely to tinker than Arts or Commerce students. Further research is required to determine if the instrument could be used as a tool to help select students for admission to technical programmes like Engineering as this result may suggest.

The engagement scale was notable because it could be that the low reliabilities in all the pilot studies suggest that the students could not yet fully relate to some of the items, implying that they are not at an "advanced" level of technological literacy. One might argue that students entering their first year of tertiary education should be at this level. In particular, some students following more technical degrees, like Engineering, Physics and Health Sciences should likely be at this level. This result is interesting and requires further investigation to compare the levels of technological literacy across diverse groups of students, as well as interviewing students to give greater insights into this area.

Based on the findings in this study, the survey instrument has been shown to be valid and reliable and can be used with confidence in future research.

\section{Acknowledgments}

The material is based upon the work supported by the University Research Committee Accredited Research Group Fellowship from the University of Cape Town. Any opinion, findings, conclusions, or recommendations expressed in this material are those of the authors and do not necessarily reflect the views of University. 


\section{Appendix: Questionnaire}

1.Technology is a person making something to solve a problem and improve quality of life.

2.I would rather play around with a technological thing than waste time first reading instructions about how to do it.

3.A CD is only technology when you put the CD into a computer and then copy music onto it.

4.I always ask permission before I use some new technological thing in case I break it.

5.It is fun figuring out how technological things work without being given instructions to follow.

6. With a new technological thing, I play with it a bit and read the manual a bitwhichever helps me the most.

7. When I see a new technological thing, the first thing I want to do is play around with it to see what it can do.

8. Technology is an idea that has been put into place by someone to help people.

9.Technology is about using scientific knowledge to make something.

10. I would rather get someone else to work a technological thing. I might get it wrong or mess it up.

11. Only with instructions, I would be able to find how to do what I want with a technological thing.

12. To find new features on the technological thing and understand it better, manuals often help if I can't figure it out myself.

13. Technology is all about computers and other electronic and electrical things like that.

14. Technology is making use of knowledge people have about something and using this to solve a problem.

15. Only if someone first shows me how to do something with a technological thing, then I can use it.

16. When using technological things, instructions tell me exactly what to do-and only then I can do it.

17. Finding out how a technological thing works is easiest by reading the manual and playing around at the same time.

18. Technology is using knowledge and skill to develop some product.

19. I would rather watch someone work with a complicated technological thing instead of trying to do it myself.

20.I like to understand a technological thing by playing with it as well as by reading more about it.

21. Things with complicated wires and parts that you don't understand are technology.

22. Something is technology because a person had a plan that was put into practice by making it.

23. I always seem to do something wrong when I try to use technological things.

24. A television is technology only when you watch a movie on it using signals from the air.

25. Technology is about solving a problem.

26. An amplifier or CD player becomes technology when it is switched on. 
27. Technology is the planning and research of something and then the making of it. 28. A washing machine thrown on a rubbish dump with no motor or wires is no longer technology. It is just a thing.

29. I can usually use technological things only when I follow instructions. 


\section{References}

Ankiewicz, P. (1995). The planning of technology education for South African schools. International Journal of Technology and Design Education, 5, 1-10.

Ardies, J., De Maeyer, S., \& Gijbels, D. (2013). Reconstructing the pupils' attitude toward technology- Survey. Design and Technology Education: An International Journal, 18(1), 8-19.

Bame, E. A., \& Dugger Jr, W. E. (1989). Pupils'attitude towards technology: PATT-USA. In F. de Klerk Wolters, I. Mottier, J. H. Raat \& M. J. de Vries (Eds.), PATT 4 conference: Teacher education for school technology (pp. 309-319).

Boser, R., Palmer, J. D., \& Daugherty, M. K. (1998). Students attitudes toward technology in selected technology programs. Journal of Technology Education, 1O(1), 4-19.

Cohen, L., Manion, L., \& Morrison, K. (2000). Research methods in education (5th ed.). London: RoutledgeFalmer.

Collier-Reed, B. I. (2006). Pupils' experiences of technology: Exploring dimensions of technological literacy. Unpublished PhD. University of Cape Town.

Collier-Reed, B. I., Case, J. M., \& Linder, C. (2009). The experience of interacting with technological artefacts. European Journal of Engineering Education, 34(4), 295302.

Collier-Reed, B., \& Ingerman, A. (2013). Phenomenography: From critical aspects to knowledge claim. In M. Tight \& J. Huisman (Eds.), International perspectives on higher education research, 9, 243-260. Compton, V. J., \& Harwood, C. D. (2003). Enhancing technological practice: An assessment framework for technology education in New Zealand. International Journal of Technology and Design Education, 13(1), $1-26$.

Dakers, J. R. (2006). Introduction: Defining technological literacy. In J. R. Dakers (Ed.), Defining technological literacy: Towards an epistemological framework. New York: Palgrave Macmillan.

Dall'Alba, G., Walsh, E., Bowden, J., Martin, E., Masters, G., Ramsden, P., et al. (1993). Textbook treatments and students'understanding of acceleration. Journal of Research in Science Teaching, 30, 621-635.

Department of Education. (1997). Curriculum 2005: Specific outcomes, assessment criteria, range statements. Grades $1-9$.

Department of Education. (2002). Revised national curriculum statement grades R-9. Technology. Pretoria: Government Printers.

Department of Education. (2011). Curriculum and assessment policy statement (CAPS). Technology. Grades 7-9.

Field, A. (2005). Discovering statistics using SPSS: Sex, drugs and rock 'n roll. London: Sage.

Gagel, C. (1995). Technological literacy: A critical exposition and interpretation for the study of technology in the general curriculum. Doctoral Dissertation, University of Minnesota, 1995. Dissertation Abstracts International, 56, 2208A. (University Microfilms No. 9534116).

Gagel, C. W. (1997). Literacy and technology: Reflections and insights for technological literacy. Journal of Industrial Teacher Education, 34(3), 6-34. 
Garmire, E., \& Pearson, G. (2006). Tech tally: Approaches to assessing technological literacy. Washington, DC: National Academies Press.

Ingerman, $\AA^{\circ}$., \& Collier-Reed, B. I. (2011). Technological literacy reconsidered: A model for enactment. International Journal of Technology and Design Education, 21, 137-148.

International Technology Education Association (ITEA). (2000). Standards for technological literacy. Virginia: International Technology Education Association.

Jenkins, E. W. (1997). Scientific and technological literacy: Meanings and rationales. In E. W. Jenkins (Ed.), Innovations in science and technology education (Vol. VI). Paris: UNESCO.

Jones, A., Bunting, C., \& De Vries, M. J. (2013). The developing field of technology education: A review to look forward. International Journal of Technology and Design Education, 23, 191-212.

Kline, P. (1999). The handbook of psychological testing. London: Routledge.

Lewis, T. (1999). Research in technology education-Some areas of need. Journal of Technology Education, 1O(2), 41-52.

Luckay, M. B., \& Collier-Reed, B. (2011a). Admitting students with the best chance of success: Technological literacy and the technological profile inventory. Proceedings of the South African society of engineering education. University of Stellenbosch: Cape Town. 10-12 August 2011.

Luckay, M. B., \& Collier-Reed, B. (2011b). The development and validation of an instrument: The technological profile inventory-to determine first year university students' technological literacy in South Africa. Proceedings of the international conference for educational research and innovation. Madrid, Spain. 14-16 November 2011, pp. 764-772.

Luckay, M. B., \& Collier-Reed, B. (2012). Comparing the technological literacy of pre-service teachers and secondary school students in South Africa. Proceedings of EDULEARN12 conference, 2nd-4th July 2012, Barcelona, Spain, pp. 635-642.

Marton, F. (1986). Phenomenography: A research approach to investigating different understandings of reality. Journal of Thought, 21, 28-49.

National Research Council (NRC). (1996). National science education standards. Washington, DC: National Academy Press.

Noble, D. (1991). Social choice in machine design: The case of automatically controlled tools. In H. Mackay, M. Young, \& J. Beynon (Eds.), Understanding technology in education. London: Falmer Press.

Nunally, J. C. (1978). Psychometric theory. New York: McGraw-Hill.

Potgieter, C. (2012). Linking learning activities and assessment activities to learning outcomes and assessment standards when teaching technology: A case study. International Journal of Technology and Design Education,. doi:10.1007/s10798012-9226-4.

Prosser, M., \& Trigwell, K. (1999). Understanding learning and teaching: The experience in higher education. Buckingham: SRHE and Open University Press.

Prosser, M., \& Trigwell, K. (2004). Development and use of the approaches to teaching inventory. Educational Psychology Review, 16(4), 409-424. 
Prosser, M., \& Trigwell, K. (2006). Confirmatory factor analysis of the approaches to teaching inventory. British Journal of Educational Psychology, 76, 405-419.

Pudi, T. I. (2007). Understanding technology education from a South African perspective. Pretoria: Van Schaik.

Raat, J. H., \& de Vries, M. J. (1985). What do 13-year old pupils think about technology? The conception of and the attitude towards technology of 13-year old girls and boys. Paper presented at the science and technology education and future human needs conference of the International Council of Scientific Unions, Bangalore.

Rose, L. C., Gallup, A. M., Dugger, W. E, Jr, \& Starkweather, K. N. (2004). The second installment of the ITEA/Gallup poll and what it reveals as to how Americans think about technology. Technology Teacher, 64(1), 1.

Rose, L. C., \& Jr Dugger, W. E. (2002). ITEA/Gallup poll reveals what Americans think about technology. A report of the survey conducted by the Gallup Organization for the International Technology Education Association. Technology Teacher, 61(6 insert), $1-8$.

Saskatchewan Education. (2001). 1999 Provincial learning assessment in technological literacy, (p. 69).

Stevens, A. (2005). Technology teacher education in South Africa. PATT-15: Technology education and research: Twenty years in retrospect (2005) (cited 03 July 2013). www.iteaconnect.org/Conference/ PATT/PATT15/Stevens.pdf.

Tabachnick, B. G., \& Fiddell, L. S. (2007). Using multivariate statistics. Needum Heights, MA: Pearson/ Allyn and Bacon.

Tamir, P. (1991). Factors associated with the acquisition of functional knowledge and understanding of science. Research in Science and Technological Education, 9(1), 17-37.

Trigwell, K. (2000). Phenomenography: Variation and discernment. In C. Rust (Ed.), Improving student learning, Proceedings of the $19997^{\text {th }}$ International Symposium, Oxford Centre for Staff and Learning Development (pp. 75-85). Oxford: Oxford.

Trigwell, K. (2002). Approaches to teaching design subjects: A quantitative analysis. Art, Design Communication in Higher Education, 1, 69-80.

Van Rensburg, S. J., Myburgh, C. P. H., \& Ankiewicz, P. (1996). Curriculum development for technology in South Africa: Gender issues. Paper presented at the GASAT 8 conference, Ahmedabad, India, 5-10 January.

Volk, K., Yip, W. M., \& Lo, T. K. (2003). Hong Kong pupils' attitude toward technology: The impact of design and technology programs. Journal of Technology Education, 15(1), $48-63$.

Waetjen, W. B. (1993). Technology education. Journal of Technology Education, 4(2), 5-10. Williams, P. J. (2005). Technology education in Australia. Proceedings of the pupils' attitude toward science conference 15, the Netherlands, April 2005. 